\title{
Predictors of vascular complications among type 2 diabetes mellitus patients at University of Gondar Referral Hospital: a retrospective follow-up study
}

Haileab Fekadu Wolde ${ }^{1 *}$, Asrat Atsedeweyen ${ }^{1}$, Addisu Jember ${ }^{1}$, Tadesse Awoke ${ }^{1}$, Malede Mequanent ${ }^{1}$, Adino Tesfahun Tsegaye ${ }^{1}$ and Shitaye Alemu ${ }^{2}$

\begin{abstract}
Background: Type 2 Diabetes Mellitus is a serious metabolic disease that is often associated with vascular complications. There are 1.9 million people living with Diabetes in Ethiopia; diabetes mellitus is found to be the ninth leading cause of death related to its complications. Although the rate of vascular complications continues to rise, there is limited information about the problem. This study aimed to estimate the incidence and predictors of vascular complications among type 2 diabetes mellitus patients at University of Gondar Referral Hospital.

Methods: Institution based retrospective follow-up study was conducted at University of Gondar Referral Hospital with 341 newly diagnosed type 2 DM patients from September 2005 to March 2017 and the data were collected by reviewing their records. Schoenfeld residuals test and interaction of each covariate with time were used to check proportional hazard assumption. The best model was selected by using Akaike Information Criteria (AIC). Hazards ratio (HR) with its respective 95\% confidence interval were reported to show strength of association.

Result: The selected patients were followed retrospectively for a median follow up time of 81.50 months (Inter quartile range $(I Q R)=67.2-103.3$ ). The mean age ( \pm Standard deviation $(S D)$ ) of patients at baseline was $51.7(S D: \pm 11.5$ years) and $57.48 \%$ were females. The incidence rate of vascular complications was 40.6 cases/ 1000 person years of observation. The significant predictors for vascular complications where found to be male sex (Adjusted hazard ratio (AHR) $=0.50$, $95 \% \mathrm{Cl}: 0.27,0.94)$, having hypertension at baseline (AHR $=3.99,95 \% \mathrm{Cl}: 1.87,8.56)$, positive protein urea at base line $(A H R=1.69,95 \% \mathrm{Cl}: 1.03,2.78)$, high density lipoprotein cholesterol(HDL-C) level $\geq 40 \mathrm{mg}$ per deciliter (mg/dl) $(A H R=0.43,95 \% \mathrm{Cl}: 0.24,0.77)$, low density lipoprotein cholesterol(LDL-C) level $>100 \mathrm{mg} / \mathrm{dl}(\mathrm{AHR}=3.05,95 \% \mathrm{Cl}: 1.47$, $6.35)$ and triglyceride $>150 \mathrm{mg} / \mathrm{dl}(\mathrm{AHR}=2.74,95 \% \mathrm{Cl}: 1.28,5.84)$.

Conclusion: The incidence of vascular complications among type 2 diabetes patients remains a significant public health problem. Hypertension at baseline, LDL-C> $100 \mathrm{mg} / \mathrm{dl}$, triglyceride $>150 \mathrm{mg} / \mathrm{dl}, \mathrm{HDL}-\mathrm{C} \geq 40 \mathrm{mg} / \mathrm{dl}$ and male sex were significant predictors of vascular complication. In the light of these findings targeted interventions should be given to diabetes patients with hypertension comorbidity and dyslipidemia at follow up clinics.
\end{abstract}

Keywords: Incidence, Predictor, Type 2 diabetes

\footnotetext{
* Correspondence: haileabfekadu@gmail.com

${ }^{1}$ Department of Epidemiology and Biostatistics, Institute of Public Health,

College of Medicine and Health Sciences, University of Gondar, Gondar,

Ethiopia

Full list of author information is available at the end of the article
}

(c) The Author(s). 2018 Open Access This article is distributed under the terms of the Creative Commons Attribution 4.0 International License (http://creativecommons.org/licenses/by/4.0/), which permits unrestricted use, distribution, and reproduction in any medium, provided you give appropriate credit to the original author(s) and the source, provide a link to the Creative Commons license, and indicate if changes were made. The Creative Commons Public Domain Dedication waiver (http://creativecommons.org/publicdomain/zero/1.0/) applies to the data made available in this article, unless otherwise stated. 


\section{Background}

Diabetes mellitus(DM) is a chronic metabolic disorder characterized by chronic hyperglycemia [1]. Globally, the prevalence of DM is $8.5 \%$ and it is estimated that one in 10 adults will have DM in the world by 2035 [2]. Sub Saharan African countries are expected to experience the fastest increase in the number of people living with type $2 \mathrm{DM}$ in the next two decades worldwide [3]. Ethiopia is the third most populous country in the African continent with 1.9 million people living with DM [4].

The seriousness of DM is largely a result of its associated vascular complications, which can be disabling and even fatal. Vascular complications caused by type 2 DM include neuropathy, nephropathy, retinopathy, coronary heart diseases(CHD), peripheral arterial diseases (PAD) and stroke [5].

In Africa, the age standardized mortality rate due to DM and its complications is estimated to be 111.3 per 100,000 population [2]. The estimated prevalence of diabetic nephropathy is $6-16 \%$ in Sub Saharan Africa [6] and $6.1 \%$ in Ethiopia [7].In addition,the prevalence of retinopathy ranges from $31.4-41.1 \%$ in Ethiopia [8]. Type $2 \mathrm{DM}$ is rapidly increasing non-communicable disease and is a major public health challenge in developing countries like Ethiopia [9] with consequences of chronicity and pre-mature death due to its vascular complications [10, 11]. In Ethiopia there were 44,655 deaths between 2012 and 2013 among people aged 20-79 years due to DM and its associated vascular complications. It was the ninth leading cause of death in Ethiopia with 22 per 1000 deaths [3, 4, 12].

There are factors which can affect the rate of vascular complications among type $2 \mathrm{DM}$ patients. Among socio demographic variables females experienced higher rates of vascular complication when compared to males as the studies done in Ethiopia and India [13, 14] but not in other studies $[15,16]$. Individuals who were hypertensive at the start of treatment have a positive association with the risk of vascular complications [15-19]. Patients with higher level of LDL-C and lower levels of HDL-C were at increased risk of developing vascular complications [20-22]. Higher levels of cholesterol and triglyceride were also positively associated with the risk of vascular complications [15].

Ethiopia is facing a double burden problem because type $2 \mathrm{DM}$ is currently increasing due to different factors such as aging, urbanization, and an increasing prevalence of obesity. Even though the rate type 2 DM and its associated vascular complications are rising, current updated information about the problem is limited. The available literatures indicated that there were discrepancies in findings for some variables, like sex. Therefore, it is imperative to conduct a study which assesses the association between incidence of vascular complications against socio-demographic, clinical and physiologic factors using a parametric survival model.

Identifying factors which influence the rate of vascular complications would provide information for health professionals, policy makers and other governmental and non-governmental organizations to maximize efforts on prevention and risk minimization of vascular complications and deaths due to the complications in the country as well as in the study area. Thus this study aimed to determine the incidence and predictors of vascular complications among type 2 DM patients in University of Gondar Referral Hospital, Ethiopia.

\section{Methods}

\section{Study design and period}

Institution based retrospective follow up study was conducted among type 2 DM patients at University of Gondar Referral Hospital. Newly diagnosed type 2 DM patients who were enrolled between September 2005 and August 2012 were followed up to March 2017.

\section{Study area and population}

University of Gondar Referral Hospital is located in the North Gondar administrative zone, Amhara National Regional State, which is about $750 \mathrm{k}$ meters (KM).

Northwest of Addis Ababa. The University of Gondar Referral Hospital is a teaching hospital which serves more than five million people in the North Gondar zone and its neighboring zones. Around 24,552 patients have chronic disease follow-up per year and among these 8880 are DM patients..Among all type 2 DM patients who are newly diagnosed between September 2005 and August 2012, newly diagnosed patients (364) who were free from any of the vascular complications at the start of treatment were selected randomly and included to the study. Patients with missing key predictor variables at baseline such as: HDL-C, LDL-C, triglyceride and hypertension status were excluded from the study.

\section{Data collection procedures and data quality control}

The study used secondary data; a data extraction check list was prepared to collect the data. Type 2 DM patients who were newly diagnosed between September 2005 and August 2012 were included. However patients who had any vascular complications mentioned at the start of the study and patients who were missing the key variables were excluded from the study. The reviewed records were identified by their medical registration or card number. The primary outcome was having any of the vascular complications such as: retinopathy, nephropathy, neuropathy, stroke, peripheral arterial dieses and coronary heart disease. These complications were determined based on the clinical decision of the physician. Diabetic retinopathy was defined by both direct and indirect ophthalmoscopy 
assessments done by retinal specialists confirmed by fundus photography. Neuropathy was defined by history of numbness, paraesthesia, tingling sensation confirmed by touch sensation by $10 \mathrm{~g}$ monofilament, vibration sense by biothesiometer and ankle reflex. Nephropathy was defined as worsening of blood pressure control, swelling of feet ankle, hands or eyes, increased need to urinate, protein in the urine with a confirmation by tests like blood test, urine test, renal function test and imaging test. Stroke is defined as patients with sudden difficulty in speech and comprehension, sudden paralysis or numbness of the face, arm or leg, sudden trouble with walking and confirmation imaging with computerized tomography (CT) scan or magnetic resonance imaging (MRI). PAD was defined by history of intermittent claudication, coldness in the lower extremities (especially when compared with the other side), weak or absent peripheral pulses in the lower extremities and confirmation via Doppler ultrasound. CHD was diagnosed by symptoms of angina, shortness of breath, a crushing sensation in the chest, pain in the shoulder or arm and sweating. Additionally CHD was confirmed by electrocardiogram (ECG) or echocardiogram [23, 24]. The patients who were included in the study were assessed for all of these vascular complications in every follow up they had in the hospital. All baseline characteristics at the start of treatment were assessed from the patient's registration document. The first characteristic assessed was the socio demographic component; this included age, sex and residence. The second characteristic assessed was the clinical component; this included hypertension comorbidity which was defined as a history of antihypertensive drug use or $\mathrm{SBP} \geq 140 \mathrm{mmHg}$ or $\mathrm{DBP} \geq$ $90 \mathrm{mmHg}$ [25], type of treatment, family history of DM, and body mass index (BMI). The third characteristic assessed was the physiologic component; this included HDL-C, LDL-C, triglyceride and total cholesterol which were categorized as high and low based on guidelines from the National Cholesterol Education Program (NCEP-III) and World Health Organization (WHO) [26, 27]. This also included creatinine, fasting blood sugar, systolic blood pressure(SBP), diastolic blood pressure(DBP) and protein urea which was defined as positive if the urine albumin concentration is between $30 \mathrm{mg}(\mathrm{mg}) / 24 \mathrm{~h}$ and $300 \mathrm{mg} / 24 \mathrm{~h}$ and negative if it is $<30 \mathrm{mg} / 24 \mathrm{~h}$. All of these characteristics of the patients were collected from their registration document. The data was collected by two health officers who had experience working in DM follow-up clinics. To control the data quality, training was given to the data collectors and their supervisor. The data extraction checklist was pre-tested for consistency of understanding the review tools and completeness of data items. The necessary adjustments were made on the final data extraction format and the filled formats were checked daily by the supervisor.

\section{Data management and analysis strategy}

The data was entered in to EPI info version 7.0 and transferred to STATA version 14.1 for analysis. Descriptive statistics were used to describe the percentage and frequency of the patients in reference to all covariates. Person-time at risk was measured starting from the time of initiation of treatment until each patient ended the follow-up. The survival experience of the patients was assessed using Kaplan-Meier survivor function. The log rank test was used to compare the survival experiences among the different groups of subjects. Schoenfeld residuals test (both global and scaled), interaction of each covariate with time and graphical methods were used to check the Cox Proportional Hazard (PH) assumption. Cox $\mathrm{PH}$ and three parametric models (Exponential, Weibull and Gompertz) models were fitted to identify the risk factors. The best model was selected by using Akaike information criteria (AIC), Bayesian information criteria (BIC) and log likelihood criteria. Goodness of fit of the model was assessed by using cox-snell residual technique. Variables having p - value less than 0.05 in the multivariable model were considered significantly associated with the dependent variable. Hazard ratio (HR) with its $95 \%$ confidence interval were computed to show the strength of association.

\section{Result}

\section{Baseline characteristics of study participants}

Out of the total of 341 newly diagnosed type $2 \mathrm{DM}$ patients, 196 (57.48\%) were females. The mean (SD) age for patients at the start of treatment was 51.7 (SD \pm $11.5)$ years. The majority of the patients $273(80.06 \%)$ were urban dwellers. About 228(66.86\%) of the patients had family history of DM and more than half of the patients 183(53.67\%) had hypertension at the start of type 2 DM treatment. Almost half of the study participants 169(49.56\%) had normal weight whereas 45(13.2\%) were obese. About 230(67.45\%) were on oral hypoglycemic agents. The majority of the patients $271(79.47 \%)$ had positive protein urea at base line. About 234(68.62\%) of the patients had HDL-C level above $40 \mathrm{mg} / \mathrm{dl}$ and more than half of the patients 186(54.55\%) had LDL-C level less than $100 \mathrm{mg} / \mathrm{dl}$. More than half of type $2 \mathrm{DM}$ patients included in the study $178(52.2 \%)$ had triglyceride level $\leq 150 \mathrm{mg} / \mathrm{dl}$. The median value for creatinine and FBS was found to be $0.78 \mathrm{mg} / \mathrm{dl}(\mathrm{IQR}=0.65-0.88)$ and $77 \mathrm{mg} / \mathrm{dl}(\mathrm{IQR}=121-178)$ respectively. The mean $( \pm \mathrm{SD})$ for SBP and DBP of the patients was $126.9( \pm 15.8)$ and $78.9( \pm 10.1)$ respectively (Table 1$)$.

\section{Vascular complications from type 2 DM}

Study subjects were followed for a median (IQR) follow up period of 81.5 months (IQR $=67.2-103.3$ ) after initiation of treatment for a total of 2391.067 person years. 
Table 1 Socio-demographic, clinical and physiologic characteristics of type 2 DM patients on anti diabetic treatment at university of Gondar referral hospital, September, 2005 - March 2017

\begin{tabular}{|c|c|c|c|}
\hline Variable & No Vascular complication $(n=244)$ & Any one of vascular complications $(n=97)$ & Total $(n=341)$ \\
\hline \multicolumn{4}{|l|}{ Sex } \\
\hline Female $n(\%)$ & $128(52.5)$ & $68(70.1)$ & $196(57.5)$ \\
\hline Male $n(\%)$ & $116(47.5)$ & 29(29.9) & $145(42.5)$ \\
\hline \multicolumn{4}{|l|}{ Residence } \\
\hline Rural n(\%) & $54(22.1)$ & $14(14.4)$ & 68(19.9) \\
\hline Urban $n(\%)$ & 190(77.9) & 83(85.6) & 273(80.1) \\
\hline \multicolumn{4}{|l|}{ Occupation } \\
\hline Unemployed n(\%) & $92(37.7)$ & $57(58.8)$ & 149(43.7) \\
\hline Government n(\%) & $71(29.1)$ & $17(17.5)$ & $88(25.8)$ \\
\hline $\mathrm{NGO} n(\%)$ & $16(6.6)$ & $4(4.1)$ & 20(5.9) \\
\hline Private $n(\%)$ & $65(26.6)$ & 19(19.6) & $84(24.6)$ \\
\hline Age $(\text { year })^{a}$ & $50.1 \pm 11.7$ & $55.9 \pm 9.9$ & $51.7 \pm 11.5$ \\
\hline \multicolumn{4}{|l|}{ Family history } \\
\hline Yes $n(\%)$ & 178(73.0) & $50(51.5)$ & 228(66.9) \\
\hline No n(\%) & $66(27.0)$ & $47(48.5)$ & 113(33.1) \\
\hline \multicolumn{4}{|l|}{ Hypertension } \\
\hline No $n(\%)$ & 148(60.7) & 10(10.3) & 158(46.3) \\
\hline Yes n(\%) & $96(39.3)$ & 87(89.7) & 183(53.7) \\
\hline \multicolumn{4}{|l|}{$\mathrm{BMI}\left(\mathrm{kg} / \mathrm{m}^{2}\right)$} \\
\hline$<18.5 n(\%)$ & $24(9.8)$ & $5(5.2)$ & $29(8.5)$ \\
\hline $18.5-24.99 n(\%)$ & 137(56.2) & $32(33.0)$ & 169(49.6) \\
\hline 25-29.99 n(\%) & $62(25.4)$ & $36(37.1)$ & $98(28.7)$ \\
\hline$\geq 30 n(\%)$ & $21(8.6)$ & $24(24.7)$ & $45(13.2)$ \\
\hline \multicolumn{4}{|l|}{ Treatment } \\
\hline $\mathrm{OHA} n(\%)$ & 163(66.8) & $67(69.1)$ & $230(67.4)$ \\
\hline Insulin n(\%) & 48(19.7) & $16(16.5)$ & $64(18.8)$ \\
\hline $\mathrm{OHA}+$ Insulin $n(\%)$ & $33(13.5)$ & $14(14.4)$ & $47(13.8)$ \\
\hline \multicolumn{4}{|l|}{ Protein urea } \\
\hline Negative $n(\%)$ & 217(89.0) & $54(55.7)$ & $271(79.5)$ \\
\hline Positive $n(\%)$ & $27(11)$ & $43(44.3)$ & $70(20.5)$ \\
\hline \multicolumn{4}{|l|}{$\mathrm{HDL}-\mathrm{C}(\mathrm{mg} / \mathrm{dl})$} \\
\hline$<40 n(\%)$ & $36(14.8)$ & $71(73.2)$ & 107(31.4) \\
\hline$\geq 40 n(\%)$ & 208(85.2) & $26(26.8)$ & 234(68.6) \\
\hline \multicolumn{4}{|l|}{$\mathrm{LDL}-\mathrm{C}(\mathrm{mg} / \mathrm{dl})$} \\
\hline$\leq 100 n(\%)$ & 174(71.3) & $12(12.4)$ & $186(54.5)$ \\
\hline$>100 n(\%)$ & $70(28.7)$ & 85(87.6) & $155(45.5)$ \\
\hline \multicolumn{4}{|l|}{ Triglyceride(mg/dl) } \\
\hline$\leq 150 n(\%)$ & 165(67.6) & 13(13.4) & $178(52.2)$ \\
\hline$>150 n(\%)$ & 79(32.4) & 84(86.6) & 163(47.8) \\
\hline \multicolumn{4}{|l|}{ Cholesterol(mg/dl) } \\
\hline$\leq 200 n(\%)$ & 184(75.4) & $27(27.8)$ & $211(61.9)$ \\
\hline$>200 n(\%)$ & $60(24.6)$ & $70(72.2)$ & 130(38.1) \\
\hline $\mathrm{FBS}(\mathrm{mg} / \mathrm{dl})^{\mathrm{b}}$ & $136(117.5-165.5)$ & 200(152-249) & 146(121-198) \\
\hline
\end{tabular}


Table 1 Socio-demographic, clinical and physiologic characteristics of type 2 DM patients on anti diabetic treatment at university of Gondar referral hospital, September, 2005 - March 2017 (Continued)

\begin{tabular}{llll}
\hline Variable & No Vascular complication $(n=244)$ & Any one of vascular complications $(n=97)$ & Total $(n=341)$ \\
\hline Creatinine $(\mathrm{mg} / \mathrm{dl})^{\mathrm{b}}$ & $0.76(0.63-0.84)$ & $0.83(0.68-1.13)$ & $0.78(0.65-0.88)$ \\
$\mathrm{SBP}(\mathrm{mm} \mathrm{Hg})^{\mathrm{a}}$ & $122.9 \pm 14.0$ & $137.0 \pm 15.8$ & $126.9 \pm 15.8$ \\
$\mathrm{DBP}(\mathrm{mm} \mathrm{Hg})^{\mathrm{a}}$ & $76.7 \pm 9.3$ & $84.5 \pm 10.0$ & $78.9 \pm 10.1$
\end{tabular}

${ }^{\mathrm{a}}$ Expressed as mean $\pm \mathrm{SD}$ and ${ }^{\mathrm{b}}$ median inter quartile range. $B M I$ body mass index, $D B P$ diastolic blood pressure, $F B S$ fasting blood sugar, $H D L-C$ high density lipoprotein cholesterol, $L D L-C$ low density lipoprotein cholesterol, SBP systolic blood pressure

During this time period the incidence of vascular complications was found to be 40.6 cases (95\% CI: 33.2, 49.5) per 1000 person year observation. From this the incidence of retinopathy was 18.4 (95\% CI: $8.8,38.6)$, nephropathy was 14.4(95\% CI: 9.8, 21.4), neuropathy was $18.9(95 \% \mathrm{CI}: 13.7$, 25.9), stroke was $17.0(95 \% \mathrm{CI}: 8.5,33.9)$, $\mathrm{CHD}$ was 16.7(95\%CI: 8.7, 32.1) and PAD was 15.1(95\%CI: 7.9, 29.0) cases per 100 person year of observation.

The cumulative probability of developing vascular complications among type 2 DM patients who were free from any of the complications at the start of treatment was 0.0423 at month $40,0.1653$ at month 70 , 0.3726 at month $100,0.5587$ at month 120 and 0.8617 at month 140 during the follow up period (Fig. 1).

\section{Predictors of vascular complication among type 2 DM patients}

After multivariable analysis using the Gompertz Cox-Regression: covariates like sex, hypertension status at baseline, protein urea at baseline, HDL-C level, LDL-C, triglyceride level were found to be independent predictors for vascular complications among type $2 \mathrm{DM}$ patients (Table 2). The risk of developing vascular complications is

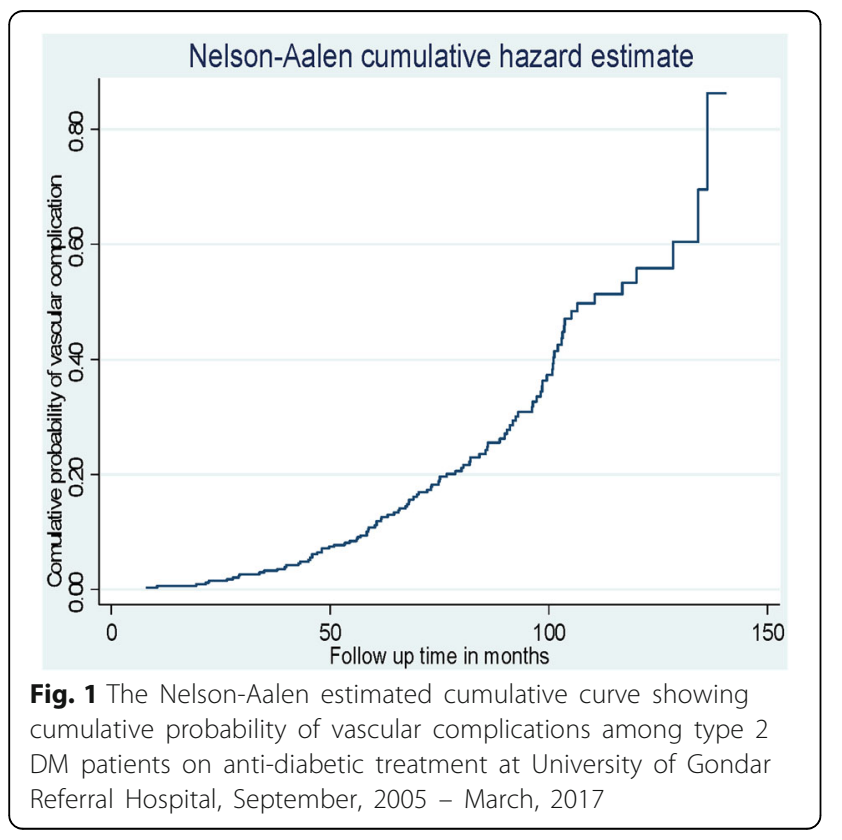

decreased by $50 \%$ among male type $2 \mathrm{DM}$ patients than female patients. Positive protein urea at the start of treatment increased the risk of vascular complications by $69 \%$ as compared to negative protein urea. The risk of vascular complications for patients who have hypertension at baseline was 3.99 times higher than that of patients who have no hypertension. HDL-C level $\geq 40 \mathrm{mg} / \mathrm{dl}$ at the start of anti-diabetic treatment decreased the risk of developing vascular complications by $57 \%$ as compared to HDL-C < $40 \mathrm{mg} / \mathrm{dl}$. The risk of vascular complications was 3.05 times higher among patients with baseline LDL-C > $100 \mathrm{mg} / \mathrm{dl}$ as compared to LDL-C $\leq 100 \mathrm{mg} / \mathrm{dl}$. Triglyceride level $>150 \mathrm{mg} / \mathrm{dl}$ at the start of anti-diabetic treatment increased the risk of vascular complications by 2.74 times as compared to LDL-C $\leq 150 \mathrm{mg} / \mathrm{dl}$.

\section{Discussion}

This study mainly investigated the incidence and predictors of vascular complications among type $2 \mathrm{DM}$ patients at University of Gondar Referral Hospital, Ethiopia. This study assessed socio-demographic, clinical and physiologic characteristics of the patients based on the records taken from their medical follow up chart. As a result, factors such as male sex, history of hypertension at baseline, positive protein urea, HDL-C level $\geq 40 \mathrm{mg} /$ $\mathrm{dl}$, LDL-C level $>100 \mathrm{mg} / \mathrm{dl}$ and triglyceride $>150 \mathrm{mg} / \mathrm{dl}$ were found to be significantly associated with vascular complications.

The cumulative incidence of vascular complications during the study period after a median follow up time of 6.8 years were $28 \%$. This result was slightly less than the study done in Taiwan [28] which showed the incidence to be $30.7 \%$ after a median follow up time of 5 years. In our study the incidence rate of vascular complications was 40.6 cases per 1000 person year observation. From this the incidence of coronary heart disease (CHD) and stroke was found to be 16.7 and 17.0 cases per 100 person year observation, respectively. This is lower than a study done in India [29] which showed the incidence rates to be 216 and 115 cases per 1000 person year observation, respectively. In our study the incidence rate of retinopathy was 18.4 cases per 100 person year observation, which is lower than another study done in Kenya [30] which showed the incidence to be 224.7 cases per 
Table 2 Multivariable analysis using the Gompertz CoxRegression model for predictor's vascular complication among type 2 DM patients in university of Gondar referral hospital September, 2005 - March 2017

\begin{tabular}{lll}
\hline Variable & Crud HR $(95 \% \mathrm{Cl})$ & Adjusted HR $(95 \% \mathrm{Cl})$ \\
\hline $\begin{array}{l}\text { Age(year) } \\
\text { Sex }\end{array}$ & $1.04(1.03,1.06)$ & $1.02(0.99,1.04)$ \\
$\quad$ & & \\
$\quad$ Female & 1 & 1 \\
$\quad$ Male & $0.47(0.31,0.73)$ & $0.50(0.27,0.94)^{*}$
\end{tabular}

Residence

Rural

Urban

1

$1.47(0.84,2.60)$

1

$0.51(0.25,1.02)$

Occupation

Unemployed

Government

NGO

Private

1

$0.80(0.41,1.57)$

$0.38(0.14,1.05)$

$0.52(0.31,0.88)$

Family history

Yes

NO

1

$2.17(1.45,3.23)$

Treatment Type

$\mathrm{OHA}$

Insulin

Insulin + OHA

$0.79(0.45,1.36)$

$0.87(0.46,1.67)$

BMI $\mathrm{kg} / \mathrm{m}^{2}$

18.5-24.99

$<18.5$

25-29.9

$0.82(0.32,2.10)$

$2.04(1.27,3.29)$

$\geq 30$

$4.22(2.47,7.21)$

Hypertension

\section{No \\ Yes}

$\mathrm{SBP}(\mathrm{mm} \mathrm{Hg})$

$\mathrm{DBP}(\mathrm{mm} \mathrm{Hg})$

$\mathrm{HDL}-\mathrm{C}(\mathrm{mg} / \mathrm{dl})$

$<40$

$\geq 40$

LDL-C(mg/dl)

$$
\leq 100
$$

$>100$

Cholesterol (mg/dl)

$$
\leq 200
$$

$>200$

\section{1}

$10.57(5.48,20.38)$

$1.03(1.0,1.04)$

$1.07(1.05,1.09)$

1

$0.12(0.07,0.18)$

1

13.12(7.14,24.10)

1

$4.67(2.99,7.28)$

Triglyceride(mg/dl)

$\leq 150$

$>150$

$\mathrm{FBS}(\mathrm{mg} / \mathrm{dl}$ )
1

8.08(4.50, 14.49)

$1.008(1.006,1.010)$
1

$0.796(0.41,1.56)$

$0.85(0.27,2.70)$

$0.83(0.39,1.74)$

1

$1.25(0.78,2.01)$

1

$0.50(0.28,1.01)$

$0.91(0.48,1.72)$

1

$1.07(0.34,3.27)$

$0.66(0.37,1.16)$

$0.84(0.44,1.61)$

1

$3.99(1.87,8.56)^{* * *}$

$0.995(0.97,1.01)$

$1.02(0.99,1.05)$

1

$0.43(0.24,0.77)^{* *}$

$3.05(1.47,6.35)^{* *}$

1

$0.76(0.43,1.36)$

1

$2.74(1.28,5.84)^{* *}$

$1.00(0.999,1.005)$
Table 2 Multivariable analysis using the Gompertz CoxRegression model for predictor's vascular complication among type 2 DM patients in university of Gondar referral hospital

\begin{tabular}{|c|c|c|}
\hline Variable & Crud HR $(95 \% \mathrm{Cl})$ & Adjusted HR (95\% Cl) \\
\hline Creatinine $(\mathrm{mg} / \mathrm{dl})$ & $1.003(0.995,1.010)$ & $100(0.995,1.009)$ \\
\hline \multicolumn{3}{|l|}{ Protein urea } \\
\hline Negative & 1 & 1 \\
\hline Positive & $4.14(2.77,6.19)$ & $1.69(1.03,2.78)^{*}$ \\
\hline
\end{tabular}
September, 2005 - March 2017 (Continued)

*** expressed as $p$-value $<0.001,{ }^{* *} p$-value $<0.01,{ }^{*} p$-value $<0.05$. BMI body mass index, $D B P$ diastolic blood pressure, FBS fasting blood sugar, $H D L-C$ high density lipoprotein cholesterol, $L D L-C$ low density lipoprotein cholesterol, SBP systolic blood pressure

1000 person year observation. This could be due to the difference in median follow-up time used by the studies. Because the study in India used longer duration of follow-up (13 years). In addition, it could be due to the age difference of the study participants in which the study in Kenya mainly used patients who were above the age of 50 years. Moreover, the difference could be due to the difference in diagnostic methods used by the studies. In contrast to this, the incidence of retinopathy (18.4), nephropathy(14.4), neuropathy(18.9) and $\operatorname{PAD}(15.1)$ cases per 100 person year observation were found to be higher than incidence of retinopathy, nephropathy, neuropathy and PAD to be $78,58,13.9,2$, cases per 1000 person year observation in India [31]. This could be due to having a short follow up time (5.7 years) used in the India study.

In this study male type $2 \mathrm{DM}$ patients accounted only $29.9 \%$ of the events and were found to have lower risk of developing vascular complications than female patients. This is in line with studies done in Ethiopia [14], India [13] and a met analysis [32] which showed female patients to have higher risk to develop vascular complications. This could be due to the hormonal differences. Because female patients encounter hormonal imbalances and decreased estrogen levels at menopause and at the same time, they lose the vasodilatory and anti-inflammatory activity of estrogen which would lead to endothelial dysfunction [33]. Another reason could be due to sex specific factors like polycystic ovarian syndrome, preeclampsia and gestational DM [34]. Another possible reason may be that women do not engage in as much physical activities as men do; physical activity contributes to improved insulin sensitivity as well as to decreased blood glucose levels and body weight [35]. In contrast to our results other retrospective follow up studies done in Iran [15] and Japan [16] showed males to be at a higher risk of developing vascular complications. Therefore, further research is needed to determine if this sex difference contributes to better outcomes in men with diabetes.

This study's findings indicated that type $2 \mathrm{DM}$ patients who have history of hypertension at base line had an 
increased risk of developing vascular complications. This result is consistent with other studies done in Iran [15], Japan [16], India [17], and Ireland [36] which showed that a history of hypertension puts the patients at a higher risk for macro and micro vascular complications. Other studies in Cameroon and Morocco investigated the association between hypertension and specific complications; in this regard type $2 \mathrm{DM}$ patients with hypertension were at increased risk of nephropathy and cardio vascular events $[18,19]$. The possible reason could be the effect of hypertension on endothelial cell structure and function that leads to enhanced growth and vasoconstriction; these changes to the endothelium have a key role in the development of arthrosclerosis and glomerulosclerosis which ultimately predisposes patients to vascular complications [37].

In this study, elevated triglyceride level $>150 \mathrm{mg} / \mathrm{dl}$ and LDL-C level $>100 \mathrm{mg} / \mathrm{dl}$ were found to increase the risk of vascular complications; however an HDL-C level $\geq$ $40 \mathrm{mg} / \mathrm{dl}$ was associated with a decreased risk of vascular complications. This result was in accordance with other studies done in India [20], Singapore [22], Zimbabwe [38] and multi-centered study involving 28 countries from Asia, Africa, Europe and South America [21]. These four studies showed that patients with higher levels of LDL- C to have higher risk to develop vascular complications but patients with the higher levels of HDL-C have a decreased risk. Our result are also consistent with another study in India which showed increased levels of triglycerides to increase the risk of developing vascular complications like stroke and CHD [29]. This could be due to their function since the function of HDL-C is to transport fats (lipids) away from the arterial wall and in to the liver. This eventually reduces risk of accumulation fats and arthroscleroses within the arterial wall and it protects the inner wall of the arteries from damage thereby reducing the risk of CHD, stroke and other vascular diseases [39]. The reverse is true for LDL-C because it transports fates (lipids) to the arteries which in turn produce arthrosclerosis in the arteries of which increases the risk of vascular complications [40]. Excess level triglycerides above the normal range $(>150 \mathrm{mg} / \mathrm{dl})$ also produces plaque in the arteries so it increases the risk of vascular complications. Furthermore, this retrospective follow up study found that patients with positive protein urea have an increased risk of having vascular complications which might be due to the fact that protein urea is an early sign of kidney damage. For this reason, patients with a positive protein urea are at an increased risk of vascular complications like nephropathy in the long run [41].

The clinical importance of this study was to provide information for health professionals and patients about factors that are associated with the risk of vascular complications, as well as, to improve the efforts on prevention. The public health importance of this study is to prevent economic loss associated with these diseases and its complications.

The limitation of this study was the use of secondary data collected retrospectively which results in incompleteness. This study assumed that all the vascular complications are caused by diabetes mellitus and considered vascular complication as a composite outcome for stroke, coronary heart disease, peripheral arterial disease, retinopathy, nephropathy, and neuropathy. This may over estimate the rate of vascular complication.

\section{Conclusion}

In this retrospective follow up study, findings showed that the incidence of vascular complications among type 2 DM patients at University of Gondar Referral Hospital remains a significant public health problem. Hypertension at baseline, LDL-C $>100 \mathrm{mg} / \mathrm{dl}$, triglyceride > $150 \mathrm{mg} / \mathrm{dl}, \mathrm{HDL}-\mathrm{C} \geq 40 \mathrm{mg} / \mathrm{dl}$ and male sex were significant predictors of vascular complications among type 2 DM patients. In light of these findings, health professionals in the DM follow up clinics should give targeted intervention for type 2 DM patients with hypertension comorbidity, dyslipidemia and positive protein urea. Patients with hypertension comorbidity should strictly control their hypertension like that of the DM.

\section{Abbreviations}

AHR: Adjusted hazard ratio; AIC: Akaike's information criteria; BIC: Bayesian information criteria; BP: Blood pressure; CHD: Coronary heart diseases;

CHR: Crude hazard ratio; CKD: Chronic kidney diseases; CT: Computerized tomography (CT); CVD: Cardiovascular diseases; DBP: Diastolic blood pressure; DM: Diabetes mellitus; ECG: Electrocardiogram; FBS: Fasting blood sugar; HDL-C: High density lipoprotein cholesterol; HR: Hazard Raito;

HTN: Hypertension; IQR: Inter quartile range; LDL-C: Low density lipoprotein cholesterol; NCEP: National cholesterol education program; PAD: Peripheral arterial disease; PH: Proportional hazard; WHO: World health organization

\section{Acknowledgments}

We would like to thank University of Gondar Referral Hospital administrative bodies and card room workers for their cooperation and permission to conduct the study. We are also thankful to the data collectors who participated in the study for their commitment.

\section{Ethical approval and consent to participate}

This work has been approved by the ethical review committee of University of Gondar, Collage of Medicine and Health Science. Permission was obtained from the University of Gondar Referral Hospital administration. The names of patients were not registered in the questionnaire and their unique MRN numbers were locked for confidentiality. Since we used secondary sources, informed consent was waived.

\section{Funding}

We are thankful for University of Gondar for the financial support to conduct the study.

Availability of data and materials

The data upon which the result based could be accessed a reasonable request. 


\section{Authors' contributions}

$\mathrm{HF}, \mathrm{AA}$ and AJ were conception and design, acquisition of data, or analysis and interpretation of data. TA, MM, AT and SA drafting the article or revising contents. All authors read and approved the final version of the manuscript.

\section{Consent for publication}

Not applicable

\section{Competing interests}

The authors declare that they have no competing interests.

\section{Publisher's Note}

Springer Nature remains neutral with regard to jurisdictional claims in published maps and institutional affiliations.

\section{Author details}

'Department of Epidemiology and Biostatistics, Institute of Public Health, College of Medicine and Health Sciences, University of Gondar, Gondar, Ethiopia. ${ }^{2}$ Department of Internal Medicine, School of Medicine, College of Medicine and Health Sciences, University of Gondar, Gondar, Ethiopia.

Received: 30 January 2018 Accepted: 17 July 2018

Published online: 31 July 2018

\section{References}

1. WHO, Definition, diagnosis and classification of diabetes mellitus and its complications. 1999.

2. WHO, Global report on diabetes. 2016

3. IDF, International diabeties federation. Diabetes Atlas 7th edition. Brusseles; 2015.

4. IDF, report of non-commncaiable disease. 2015.

5. Ahmed KA, Muni S, Ismail IS. Type 2 diabetes and vascular complications: a pathophysiologic view. Biomed Res. 2010;21(2):147-55.

6. Naicker S. Burden of end-stage renal disease in sub-Saharan Africa. Clin Nephrol. 2010;74:S13-6.

7. Yirsaw B. Chronic kidney disease in sub-Saharan Africa: hypothesis for research demand. Ann Afr Med. 2012:11(2):119.

8. Ejigu A. Brief communication: patterns of chronic complications of diabetic patients in Menelik II hospital, Ethiopia. Ethiop J Health Dev. 2000;14(1):113-6.

9. Abebe SM, et al. Increasing trends of diabetes mellitus and body weight: a ten year observation at Gondar university teaching referral hospital, Northwest Ethiopia. PLoS One. 2013;8(3):e60081.

10. Berry J, Keebler ME, McGuire DK. Diabetes mellitus and cardiovascular disease. Herz. 2004:29(5):456-62.

11. Grundy SM, et al. Diabetes and cardiovascular disease. Circulation. 1999; 100(10):1134-46.

12. IDF, DF report of non-commncaiable disease. 5th edition 2012;Atlas, Brussels: IDF.

13. Raman $R$, et al. Prevalence and risk factors for diabetic microvascular complications in newly diagnosed type 2 diabetes mellitus. Sankara Nethralaya diabetic retinopathy epidemiology and molecular genetic study (SN-DREAMS, report 27). J Diabetes Complicat. 2012;26(2):123-8.

14. Muluneh LBaEK. Correlates of time to microvascular complications among diabetes mellitus patients usingparametric and non-parametric approaches: a case study of Ayder referral hospital, Ethiopia. Ethiop J Sci Technol. 2017; 10(1):65-80

15. Sadeghpour $\mathrm{S}$, et al. Predictors of all-cause and cardiovascular-specific mortality in type 2 diabetes: a competing risk modeling of an Iranian population. Adv Biomed Res. 2016;5(1):82

16. Tanaka $S$, et al. Predicting macro-and microvascular complications in type 2 diabetes. Diabetes Care. 2013;36(5):1193-9.

17. Agrawal $R$, et al. Prevalence of micro and macrovascular complications and their risk factors in type-2 diabetes mellitus. JAPI. 2014;62:505.

18. Bentata $Y$, et al. Diabetic kidney disease and vascular comorbidities in patients with type 2 diabetes mellitus in a developing country. Saudi J Kidney Dis Transpl. 2015:26(5):1035-43.

19. Choukem SP, et al. Comparison of different blood pressure indices for the prediction of prevalent diabetic nephropathy in a sub-Saharan African population with type 2 diabetes. Pan Afr Med J. 2012;11:67.
20. Agrawal RP, et al. Prevalence of micro and macrovascular complications and their risk factors in type-2 diabetes mellitus. J Assoc Physicians India. 2014; 62(6):504-8

21. Litwak $L$, et al. Prevalence of diabetes complications in people with type 2 diabetes mellitus and its association with baseline characteristics in the multinational a 1 chieve study. Diabetol Metab Syndr. 2013;5(1):57.

22. Lekshmi Narayanan RM, et al. Peripheral arterial disease in communitybased patients with diabetes in Singapore: results from a primary healthcare study. Ann Acad Med Singap. 2010;39(7):525-7.

23. Marathe PH, Gao HX, Close KL. American Diabetes Association standards of medical care in diabetes 2017. J Diabetes. 2017:9(4):320-4.

24. Longo D, et al. Harrison's principles of internal medicine: volumes 1 and 2 New York: McGraw-Hill; 2012

25. Parati $G$, et al. European Society of Hypertension practice guidelines for ambulatory blood pressure monitoring. J Hypertens. 2014:32(7):1359-66.

26. Marchesini G, et al. WHO and ATPIII proposals for the definition of the metabolic syndrome in patients with type 2 diabetes. Diabet Med. 2004; 21(4):383.

27. Expert Panel on Detection, E. Executive summary of the Third Report of the National Cholesterol Education Program (NCEP) expert panel on detection, evaluation, and treatment of high blood cholesterol in adults (Adult Treatment Panel III). JAMA. 2001:285(19):2486.

28. Cheng $L J$, et al. A competing risk analysis of sequential complication development in Asian type 2 diabetes mellitus patients. Sci Rep. 2015;5:15687

29. Abu-lebdeh HS, Nguyen TT. Predictors of Macrovascular Disease in Patients WithType 2 Diabetes Mellitus. Mayo Foundation for Medical Education and Research. 2001;76:707-12.

30. Bastawrous A, et al. The incidence of diabetes mellitus and diabetic retinopathy in a population-based cohort study of people age 50 years and over in Nakuru, Kenya. BMC Endocr Disord. 2017:17(1):19.

31. Amutha A, et al. Incidence of complications in young-onset diabetes: comparing type 2 with type 1 (the young diab study). Diabetes Res Clin Pract. 2017;123:1-8.

32. Collaboration, E.R.F. Diabetes mellitus, fasting blood glucose concentration, and risk of vascular disease: a collaborative meta-analysis of 102 prospective studies. Lancet. 2010;375(9733):2215-22.

33. Maric-Bilkan C. Sex differences in micro-and macro-vascular complications of diabetes mellitus. Clin Sci. 2017;131(9):833-46.

34. Carpenter MW. Gestational diabetes, pregnancy hypertension, and late vascular disease. Diabetes Care. 2007;30(Supplement 2):S246-50.

35. ADA. Standards of medical care in diabetes. Diabetes Care. 2008;31:S12-54.

36. Tracey $\mathrm{ML}$, et al. Risk factors for macro-and microvascular complications among older adults with diagnosed type 2 diabetes: findings from the Irish longitudinal study on ageing. J Diabetes Res. 2016;2016:5975903.

37. Hsueh WA, Anderson PW. Hypertension, the endothelial cell, and the vascular complications of diabetes mellitus. Hypertension. 1992;20(2): 253-63.

38. Tapera, S., Prevalence and Risk Factors for Diabetes Chronic Complications in Harare, Zimbabwe, 2014. 2014, University of Zimbabwe.

39. Link JJ, Rohatgi A, de Lemos JA. HDL cholesterol: physiology, pathophysiology, and management. Curr Probl Cardiol. 2007;32(5):268-314.

40. Trialists $C T$. The effects of lowering $L D L$ cholesterol with statin therapy in people at low risk of vascular disease: meta-analysis of individual data from 27 randomised trials. Lancet. 2012:380(9841):581-90.

41. Carroll MF. Proteinuria in Adults: A Diagnositc Approach. Am Fam Physician. 2000:62(6):1333-40.

Ready to submit your research? Choose BMC and benefit from

- fast, convenient online submission

- thorough peer review by experienced researchers in your field

- rapid publication on acceptance

- support for research data, including large and complex data types

- gold Open Access which fosters wider collaboration and increased citations

- maximum visibility for your research: over $100 \mathrm{M}$ website views per year

At BMC, research is always in progress.

Learn more biomedcentral.com/submission 